\title{
Expanded criteria for Video Endoscopic Inguinal Lymphadenectomy (VEIL) in penile cancer: palpable lymph nodes
}

Alexandre Stievano Carlos, Pedro Romanelli, Ricardo Nishimoto, Luis M. Montoya, César Augusto Braz Juliano, Renato Meirelles M. da Costa Jr, Antonio C. L. Pompeo, Marcos Tobias-Machado

ABC Medical School (ASC, CABJ, RMMCJr, ACLP, MTM), Santo André; Alberto Cavalcanti Hospital $(P R, R N)$, Belo Horizonte and National Institute of Neoplastic Diseases (LMM), Lima, Peru

\begin{abstract}
Introduction: Open inguinal lymphadenectomy is the gold standard for the treatment of inguinal metastasis in patients with penile cancer (PC). Recently the Video Endoscopic Inguinal Lymphadenectomy (VEIL) was proposed as an option to reduce the morbidity of the procedure in patients without palpable inguinal lymph nodes (PILN), however the oncological equivalency in patients with PILN remains poorly studied. The aims of this video are the demonstration of VEIL in patients with PILN and present the preliminary experience comparing patients with and without PILN.

Materials and Methods: The video illustrates the procedure performed in two cases that were previously underwent partial penectomy for PC with PILN. Data from the series of 15 patients (22 limbs operated) with PILN underwent VEIL were compared with our series of VEIL in 25 clinically NO patients (35 limbs operated).

Results: The comparison between the groups with and without PILN found, respectively, these outcomes: age 52,45 x 53,2 years, operative time 126,8 x 95,5 minutes, hospital stay 5. x 3.1 days, drainage time 6.7 x 5.7 days, 9 resected lymph nodes on average in both groups, global complications $32 \%$ x 26\%, cellulitis $4.5 \%$ x $0 \%$, lymphocele $23 \%$ in both groups, skin necrosis $0 \% \times 3 \%$, myocutaneous necrosis $4.5 \% \times 0 \%$, pN+33\% x 32\%, cancer specific mortality 7\% x 5\% and mean follow-up $17.3 \times 35.3$ months. None of the variables presented $\mathrm{p}<0.05$. Conclusions: VEIL is a safe complementary procedure for treatment of PC, even in patients with PILN. Oncological results in patients with PILN seem to be appropriate but are still very premature. Prospective multicenter studies with larger samples and long-term follow-up should be conducted to determine the oncological equivalence of VEIL compared with open surgery in patients with PILN.
\end{abstract}

\section{ARTICLE INFO}

Available at: www.brazjurol.com.br/videos/november_december_2013/Carlos_893_894video.htm

Int Braz J Urol. 2012; 39 (Video \#14): 893-4

Submitted for publication:

Correspondence address:

October 01, 2013

Alexandre Stievano Carlos, MD

Department of Urology, ABC Medical School 821 Principe de Gales Avenue, Annexe II,

Accepted after revision:

Santo Andre, SP, 09060-650, Brazil Telefone: + 5511 4993-5462 November 30, 2013

E-mail: ale_carlos@uol.com.br 


\section{EDITORIAL COMIMENT}

In the present video entitled "Expanded criteria for video endoscopic inguinal lymphadenectomy in penile cancer", the authors present 2 cases of penile cancer in the patients with palpable inguinal lymphadenopathy who were managed using a video endoscopic inguinal lymphadenectomy approach (VEIL). The video nicely depicts the surgical principles and potential merits of such a minimally invasive surgical approach however I would caution the authors on stating that a VEIL approach is an oncological equivalent surgical option to managing inguinal lymph nodes in penile cancer patients with palpable lymph nodes. I believe this video and abstract would be suitable for publication if the authors could appropriately amend their conclusions by stating that VEIL remains a poorly studied surgical option to the management of palpable inguinal lymphadenopathy among penile cancer patients. In conclusion, the present video highlights that it is in fact feasible to conduct such a VEIL approach in this clinical context although its oncological efficacy remains to be determined. Lastly, the authors could encourage cooperative groups like SWOG or the EORTC and/or maybe international high volume penile cancer treatment centers to do such a prospective study which would contrast the oncological outcomes and benefits of the VEIL versus open inguinal lymphadenectomy approach in appropriately matched cohorts of patients.

Philippe E. Spiess, MD Associate Professor, Department of GU Oncology Moffitt Cancer Center Video Section Editor, International Brazilian Journal of Urology E-mail: philippe.spiess@moffitt.org 